\title{
Geburtshilfliche Operationen
}

Zangenertraktion . . . . . . . . . . . . . . . 224

bei geradstehendem Kopf . . . . . . . . . . . 224

bei schrägstehendem Kopf . . . . . . . . . . . 237

bei tiefem Querstand . . . . . . . . . . . 250

bei hinterer Hinterhauptslage. . . . . . . . . . 262

bei Vorderhauptslage . . . . . . . . . . . . . 274

bei Gesichtslage. . . . . . . . . . . . . . . . . 288

am SteiB. . . . . . . . . . . . . . . . . . . 346

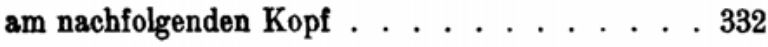

Vakuumextraktion . . . . . . . . . . . . 193

Operationen bei Beekenendlage

Manualhillo . . . . . . . . . . . . . . . 318

nach Bracht . . . . . . . . . . . . . . 320

nach Müller . . . . . . . . . . . . . . . . . 322

nach Lövset . . . . . . . . . . . . . . . . 323

klassische Armlösung . . . . . . . . . . . . . . 325

Veit-Smelliescher Handgriff . . . . . . . . . . 329

Manuello Ertraktion . . . . . . . . . . . . . . . 333

Wondung . . . . . . . . . . . . 390

aus Querlage . . . . . . . . . . . 390

aus Kopflage. . . . . . . . . . . . . . 507

Zweifingerwendung nach Braxton-Hicks . . . . . 511

Zerstuekelnde Operationen . . . . . . . . . . . . 407

Dekapitation . . . . . . . . . . . 407

Embryotomie . . . . . . . . . . 411

Perforation. . . . . . . . . . 606

Kraniotraxie . . . . . . . . . . . 610

Episiotomio . . . . . . . . . . . . . . 212 